Çukurova Üniversitesi Mühendislik Fakültesi Dergisi, 36(3), ss. 743-754, Eylül 2021

Cukurova University Journal of the Faculty of Engineering, 36(3), pp. 743-754, September 2021

\title{
Fotovoltaik Panel ve Batarya Entegre Sistemler için Yeni Bir Interleaved Tabanlı Çok Portlu İzole DA-DA Dönüştürüiü Analizi
}

\author{
Murat Mustafa SAVRUN"1, Alihan ATAY2 \\ ${ }^{1}$ Adana Alparslan Türkeş Bilim ve Teknoloji Üniversitesi, Mühendislik Fakültesi, Elektrik- \\ Elektronik Mühendisliği Bölümü, Adana \\ ${ }^{2}$ Solvaytech Mühendislik Endüstri ve Ticaret Ltd. Şti., Adana
}

Geliş tarihi: 02.07.2021 Kabul tarihi: 13.09.2021

$\ddot{O} z$

$\mathrm{Bu}$ çalışmada, fotovoltaik (FV) panel ile çalışan ve batarya destekli sistemler için etkin bir kontrol yapısına sahip interleaved tabanlı çift yönlü çok portlu izole yeni bir DA-DA dönüştürücü önerilmektedir. Önerilen dönüştürücü, üretim/depolama/yük birimleri arasındaki optimum güç akışını denetlemek için tasarlanmıştır. Tasarlanan sistemde, FV panel ve batarya arası güç transferi interleaved DA-DA dönüştürücünün sol kol anahtarlarının kontrolü ile sağlanırken, enerji üretim/depolama birimleri ile yükler arası güç transferi ilgili devrenin sağ kol anahtarlarının kontrolü ile sağlanmaktadır. Yük tarafının izolasyonunu sağlayan yüksek frekans transformatörünün (YFT) ikincil tarafında bulunan iki yarım köprü devresi ile birbirinden bağımsız kontrol edilebilen ve farklı gerilim seviyelerine sahip iki port oluşturulmaktadır. Önerilen dönüştürücüde portlar arasındaki güç akışı kontrol döngüleri arasında yumuşak geçiş yapabilen çok döngülü bir kontrol şeması tarafından gerçekleştirilmektedir. Önerilen çok portlu dönüştürücünün uygulanabilirliğini ve etkinliğini doğrulamak için, PSIM programında simülasyon çalışmaları gerçekleştirilmiştir. Önerilen dönüştürücünün performansı farklı ışınım ve yüklenme durumları gibi dinamik koşullar altında analiz edilmiştir. Güç akış yetenekleri ve yüksek verimlilik değerleri (>\%98) önerilen dönüştürücünün uygulanabilirliğini ve etkinliğini doğrulamaktadır.

Anahtar Kelimeler: Çok portlu dönüştürücü, DA-DA dönüştürücü, Fotovoltaik panel, Batarya

\section{Analysis of a New Interleaved-Based Multi-Port Isolated DC-DC Converter for Photovoltaic Panel and Battery Integrated Systems}

\begin{abstract}
In this study, a new interleaved-based bidirectional isolated multi-port DC-DC converter with an effective control structure for photovoltaic (PV) panel powered and battery buffered systems is proposed. The proposed converter is designed to perform the optimum power flow between generation/storage/load units. In the designed system, the power transfer between the PV panel and the battery is provided by the control of the left leg switches of the interleaved DC-DC converter, while the power transfer between the energy generation/storage units and the loads is provided by the control of the right leg switches of the relevant circuit. With two half-bridge circuits on the secondary side of the high-frequency transformer (HFT), which provides load side isolation, two ports with different voltage levels and which can be controlled independently of each other are formed. In the proposed converter, the power flow between the ports is handled by a multi-loop control scheme that is able to smoothly switch between control loops. Simulation studies have been conducted in the PSIM program to verify the viability and effectiveness of the proposed multiport converter. The
\end{abstract}

*Sorumlu yazar (Corresponding author): Murat Mustafa SAVRUN,msavrun@atu.edu.tr 
Fotovoltaik Panel ve Batarya Entegre Sistemler için Yeni Bir Interleaved Tabanlı Çok Portlu İzole DA-DA Dönüşı̈̈rücü Analizi

performance of the proposed converter is analyzed under dynamic conditions such as different radiation and loading conditions. The power flow capabilities and high efficiency values ( $>98 \%)$ validates the viability and effectiveness of the proposed converter.

Keywords: Multi-port converter, DC-DC converter, Photovoltaic panel, Battery

\section{GíRiş}

Hizla tükenen fosil yakitlara ve artan sera gazı emisyonlarına bağlı olarak yenilenebilir enerji kaynaklarının (YEK) kullanımı elektrikli araçlarda, mikro şebekelerde ve dağıtık üretimde büyük oranda artmaktadır [1]. Ancak YEK tarafindan üretilen gücün kapasitesi ve kullanılabilirliği, rüzgar hızı, güneş 1şınımı/sıcaklığı gibi değişken doğa koşulları gereği kararsızdır. Bu nedenle, YEK ile beslenen sistemler yüklere kesintisiz güç sağlamak için sıklıkla enerji depolama üniteleri ile donatılırlar. YEK tarafından üretilen güç, doğrudan yüklere veya depolama birimlerine aktarılırken, enerji depolama birimleri yenilenebilir enerji kaynaklarının anlık üretim değerlerine veya yüklerin taleplerine bağlı olarak şarj veya deşarj edilmektedir. Bu bağlamda YEK, enerji depolama birimleri ve yükler arasındaki güç aktarım arayüzü olan güç elektroniği sistemleri büyük bir öneme sahiptir. Birden fazla enerji kaynağının veya enerji depolama elemanının yer aldığı sistemlerde güç akışını sağlamak için kullanılan yapılar genel olarak çok portlu dönüştürücüler olarak adlandırılmaktadır [2]. Şekil 1'de geleneksel çok portlu dönüştürücü yapısı gösterilmektedir.
Geleneksel çok portlu dönüştürücülerde her bir bağlantı noktasının güç akışını kontrol etmek için bireysel güç elektroniği dönüştürücülerine ihtiyaç duyulmaktadır. Şekil 1'de gösterildiği gibi enerji depolama birimleri için çift yönlü DA-DA dönüştürücü [3] kullanılırken FV Panel ve rüzgar türbini gibi YEK'ler için tek yönlü DA-DA dönüştürücü [4] ve AA-DA doğrultucu kullanılması gerekmektedir. Bireysel güç elektroniği dönüştürücüsü kullanımı hem sistem kompleksitesini hem de toplam maliyeti arttırmaktadır. Bu dezavantajları ortadan kaldırmak için YEK'ler ile enerji depolama birimlerinin birbirine entegre edildiği yeni nesil çok portlu DADA dönüştürüicüler üzerine [5-9] araştırmacılar tarafından literatürde son zamanlarda s1klıkla çalışılmaktadır.

Çok portlu dönüştürücüler kendi içerisinde tam izole ve izole olmayan sistemler olmak üzere ikiye ayrılmaktadır. İzole olmayan DA-DA dönüştürücüler [10-13] geleneksel azaltan, yükselten ve azaltan-yükselten topolojilerinden türetilmiş olup düşük ve orta güçlü uygulamalarda sıklıkla kullanılmaktadır. İzole olmayan topolojiler, YFT'nin olmaması nedeniyle daha basit ve kompakt bir yapı ile avantaj sağlarken, izolasyon ve esnek gerilim aralığı sağlayamamaktadır.

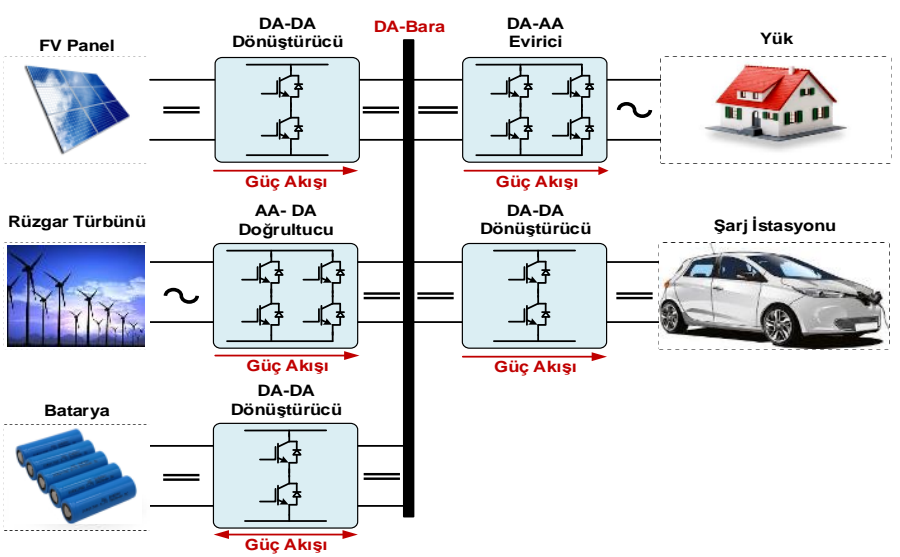

Şekil 1. Geleneksel çok portlu dönüştürücüler 
İzole çok portlu dönüştürücüler, YFT dönüş oranı ile esnek gerilim aralıkları sağlamaktadır. Bu nedenle, izole dönüştürücüler düşük çıkış gerilimine sahip YEK'ler ile donatılmış sistemler için iyi bir adaydır. Ancak, yüksek dönüş oranlı YFT'ler ile donatılmış topolojiler sınırlı gerilim kazancı sağlamalarının yanı sıra nispeten yüksek iletim kayıplarına sebep olurlar [14]. İzole topolojilerde iletim kayıplarının azaltmak için sıfır gerilim veya sıfır akım anahtarlama [15-17] teknikleri sıklıkla uygulanmaktadır. Bunun yanı sıra, izole çok portlu DA-DA dönüştürücüler kendi içerisinde tamamen izole veya kısmen izole olmak üzere iki alt sınıfta incelenmektedir. Tamamen izole topolojilerde bulunan bütün bağlantı noktaları farklı bir toprak döngüsüne sahip olup galvanik izole durumdadır. Genellikle çift aktif köprü $[18,19]$ ve tam köprü dönüştürücü $[20,21]$ topolojilerinden türetilmiş olan tamamen izole topolojiler yüksek güçlü uygulamalarda sıklıkla kullanılmaktadır. Bunun yanı sıra, çok yüksek güç gerektirmeyen uygulamalarda ise yarım köprü [22] topolojisinden türetilmiş çok portlu dönüştürücüler kullanılmaktadır. Yarım köprü topolojisine sahip sistemler görev döngülerinin sınırlarından dolayı esnek gerilim aralığı sağlayamamaktadır. Ayrıca, bu tip topolojiler yüksek anahtarlama elemanı sayısına sahiptir. Kismen izole topolojilerde, oluşturulan çok portlu yapının iki ve daha fazla portu aynı toprak döngüsüne sahip olup, geriye kalan portlar ise YFT sayesinde farklı bir toprak döngüsüne sahiptir [23-25]. K1smen izoleli topolojilerde YEK ile enerji depolama ünitesi arasındaki güç akış kontrolü mevcut ortak anahtarlama elemanları ile sağlanarak entegre bir çift yönlü DA-DA dönüştürücü topolojisi tasarlanır [26,27]. Böylelikle, anahtarlama elemanlarının sayısı azaltılırken YFT sargılarının artmasının da önüne geçilir. $\mathrm{Bu}$ bağlamda, bazı çalışmalar YFT'nin birincil tarafında bağlantı noktası artışını ele alırken bazıları ise YFT'nin ikincil tarafında bağlantı noktası artışı üzerine odaklanmıştır. [28] çalışmasında, ikincil taraf tam köprü doğrultucu iki DA çıkış portu elde etmek için ortak bir toprak ve farklı pozitif terminaller ile iki ayrı anahtarlama koluna bölünmüştür. Azaltılmış anahtarlama yapısına sahip entegre dönüştürücüler içerisinde interleaved yapılar ön plana çıkmaktadır. Tek taraflı interleaved yapı ile üç port entegrasyonu sağlanabilirken [29] çift taraflı interleaved yapılar ile dört port entegrasyonu yapilabilmektedir [30]. Tek taraflı interleaved yapıların ikincil tarafı için aday birçok köprü, köprüsüz, resonant doğrultucu yapıları bulunmaktadır [29,31]. Bu topolojilerde her ne kadar ek anahtarlama elemanları ile yüksek kazanç hedeflense de bağımsız yük bağlantısı ve yüklerin bireysel kontrolü sağlanmamaktadır.

Yapılan literatür taraması, çok portlu dönüştürücülerin anahtarlama elemanlarının fazlalığını, yüksek kontrol kompleksitesini ve yüksek işlem yükünü ortaya koymaktadır. Bu çalışmada, azaltılmış anahtarlama elamanı, düşük maliyet ve yüksek verim avantajları ile interleaved tabanlı çift yönlü çalışabilen çok portlu izole yeni bir DA-DA dönüştürücü sunulmaktadır. Önerilen topolojinin sunduğu yenilikler; (i) nispeten düşük gerilimli batarya sisteme kolaylıkla entegre edilmekte, (ii) çeşitli enerji üretim/depolama birimleri için çoklu giriş bağlantı noktaları ve birbirinden bağımsız kontrol edilebilen çift çıkış bağlantı noktası sağlanmakta, (iii) düşüuk anahtarlama elemanı sayısı ile düşük maliyetli bir güç elektroniği çözümü elde edilmekte ve (iv) enerji birimleri ve yükler arasındaki güç transferini yönetmek için kontrol döngüleri arasında anlık geçişe izin veren çok döngülü bir kontrol yapısı gerçekleştirilmektedir. Makalenin geri kalanı şu şekilde düzenlenmiştir: Bölüm 2'de, önerilen çok portlu dönüştürücü topolojisini tanıtmakta ve çalışma prensibini açıklamaktadır. Bölüm 3'te, önerilen dönüştürücünün çok döngülü kontrol yapısı sunulmaktadır. Performans analizi sonuçları Bölüm 4'te sunulmaktadır. Bölüm 5, ilgili tartışma ile birlikte sonuçları ortaya koymaktadır.

\section{2. ÖNERILLEN DÖNÜSTÜRÜCÜ VE ÇALIŞMA PRENSIBí}

Önerilen çok portlu DA-DA dönüştürücünün güç devresi Şekil 2'de gösterilmekte olup interleaved alçaltan-yükselten dönüştürücü, YFT ve yarım köprü doğrultuculardan oluşmaktadır. Önerilen dönüştürücü $\mathrm{FV}$ panelden batarya ve yüklere ve FV panel ve bataryadan yüklere optimum güç akışını sağlamak ve aynı zamanda yük gerilimlerini istenilen seviyede sabit tutmak için tasarlanmıştır. 
Fotovoltaik Panel ve Batarya Entegre Sistemler için Yeni Bir Interleaved Tabanlı Çok Portlu İzole DA-DA Dönüştürü̈cü Analizi

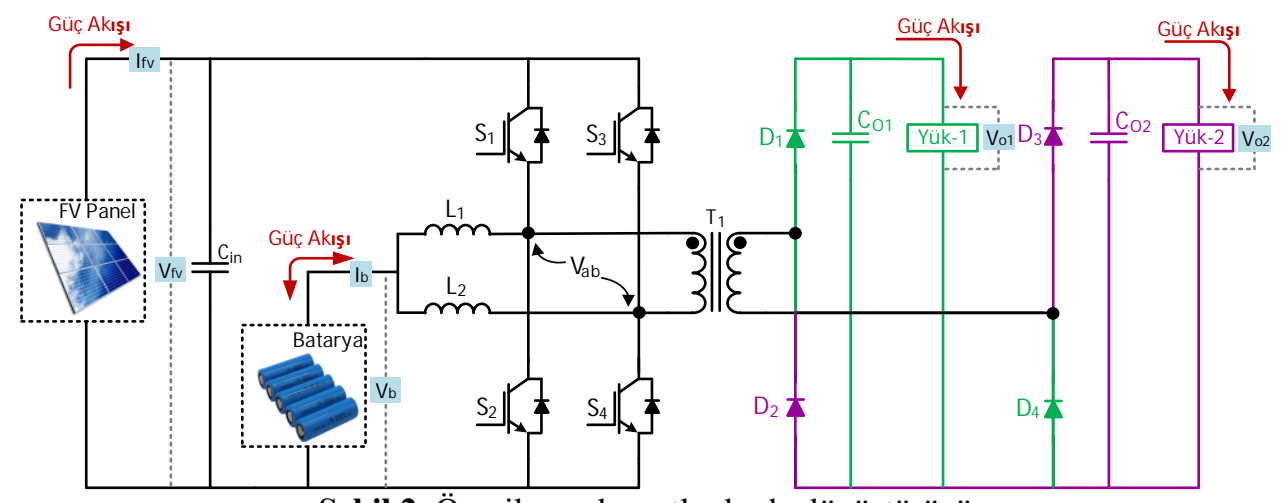

Şekil 2. Önerilen çok portlu dc-dc dönüştürücü

Interleaved DA-DA dönüştürücü nispeten düşük gerilimli bataryanın entegre edilmesini sağlamasının yanı sıra FV panel ile batarya arasında çift yönlü güç transferine de olanak sağlamaktadır. Ayrıca, önerilen dönüştürücü YFT dönüş oranı ile yüksek gerilim kazancı sağlamayı da mümkün kılmaktadır. YFT'nin ikincil tarafı yarım köprü doğrultucu devreleri ile donatılmıștır.

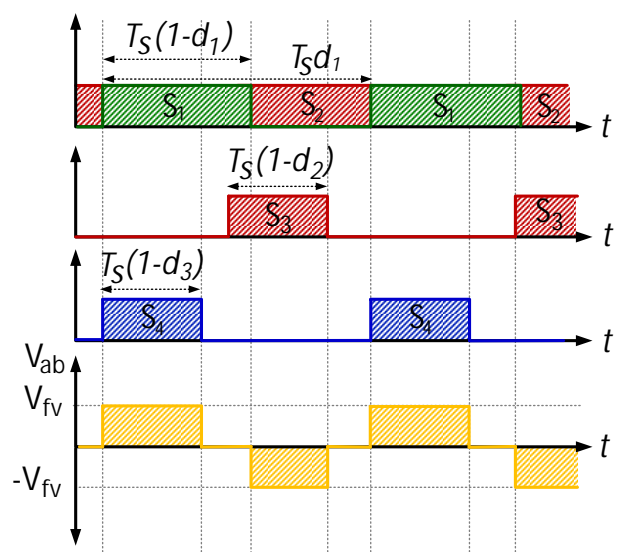

Şekil 3. Önerilen dönüştürücünün kontrol yöntemi

Önerilen dönüştürücünün anahtarlama durumları Şekil 3'te verilmiştir. Birincil tarafta bulunan dört anahtarlama elemanı farklı kontrol döngüleri tarafindan tetiklenmektedir. $S_{1}$ ve $S_{2}$ anahtarları maksimum güç noktası izleme (MPPT), sabit akım (SA) ve sabit gerilim (SG) kontrol döngüleri tarafından tetiklenirken, $S_{3}$ ve $S_{4}$ anahtarları yüklerin gerilim regülasyonlarını sağlamak için yük kontrol döngüleri tarafından tetiklenmektedir. $S_{1}$ ve $S_{2}$ anahtarlama elemanlarının açma/kapama sinyalleri birbirini tamamlayan şekilde çalışmaktadır. $T_{s}$ bir anahtarlama periyodunu temsil etmektedir. $d_{l}$ olarak adlandirılan görev döngüsü değeri MPPT, SA ve SG kontrol döngülerinin PI çıkışlarına bağlı olarak değişkenlik göstermektedir. $\mathrm{S}_{3}$ ve $\mathrm{S}_{4}$ anahtarlama elemanlarının görev döngüsü değerleri $\left(d_{2}\right.$ ve $\left.d_{3}\right)$ ise maksimum $\% 50$ değerine ulaşabilmektedir. Bunun nedeni $\mathrm{S}_{3}$ ve $\mathrm{S}_{4}$ anahtarlarının birbirleri arasında $180^{\circ}$ derece faz fark1 ile tetiklenmesidir. $\mathrm{Bu}$ noktada, ilgili anahtarların \%50 görev döngüsünü aşmaları halinde alt ve üst anahtarlar aynı anda açılacak ve kısa devre olacaktır. $S_{3}$ ve $S_{4}$ anahtarlarının görev döngüsü değerleri yük kontrol döngülerine bağlı olarak belirlenmektedir.

\section{KONTROL YAPISI}

Önerilen çok portlu DA-DA dönüştürücü sisteminin kontrolcüsü Şekil 4'te gösterildiği üzere MPPT, SA, SG ve yük kontrol döngüleri olmak üzere çoklu kontrol döngülerinden oluşmaktadır. Önerilen kontrolcü yapısı FV panel/batarya/yükler arasında optimum güç akışını sağlayabilmek için Şekil 5'te verilen yönetim algoritması koordinasyonunda $\mathrm{FV}$ panel gücünü, yüklerin talebini ve bataryanın durumunu göz önüne bulundurarak en uygun kontrol döngüsünü seçmektedir. Kontrolcünün temel öncelikleri şunlardır; (i) yüklere kesintisiz güç sağlamak ve gerilimlerinin sürekliliğini sağlamak, (ii) bataryanın servis ömrünü uzatmak için SA/SG şarj algoritmalarını uygulamak, (iii) FV panelin maksimum güç üretiminin sağlamak. 


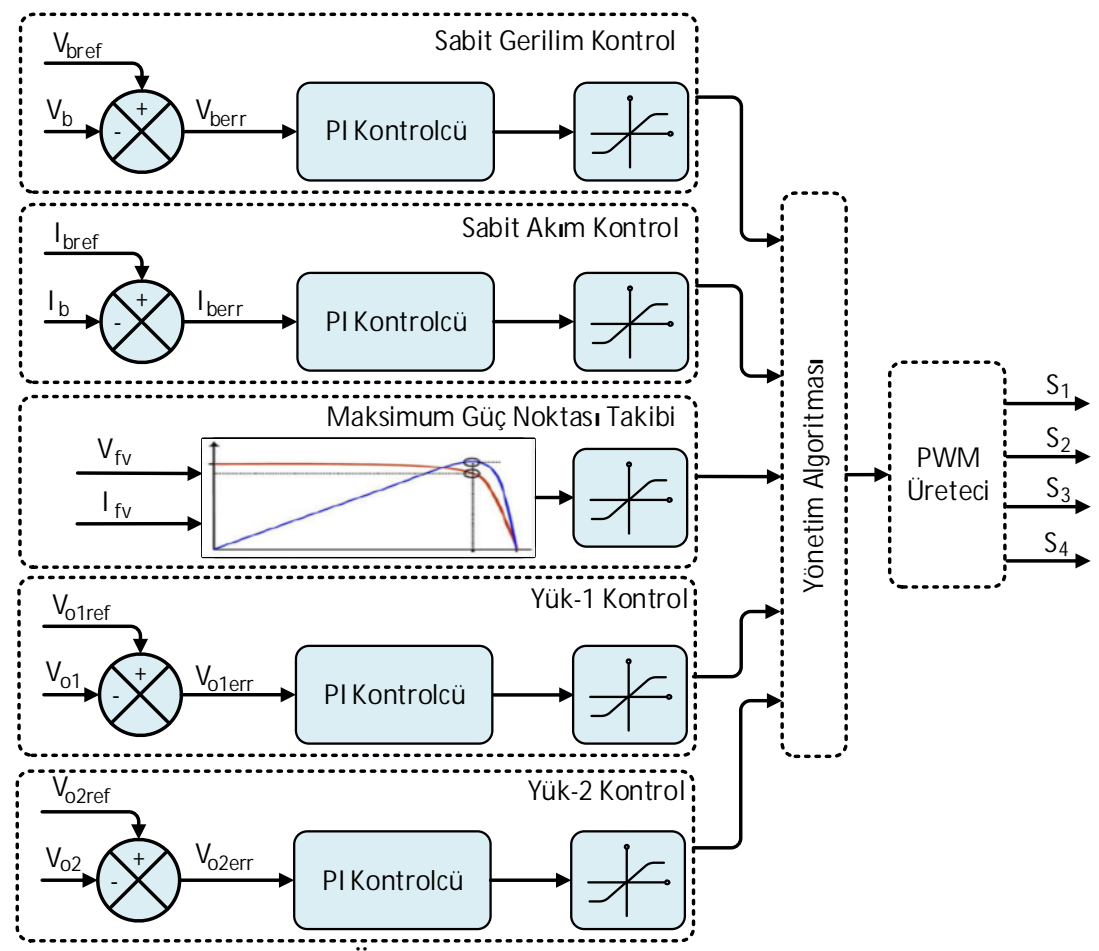

Şekil 4. Önerilen topolojinin etkin kontrolcüsü

Önerilen topoloji FV panelin ve yüklerin anlık durumlarına göre iki farklı çalışma moduna sahiptir. Mod 1, yüklerin talep ettiği güçten daha düşük bir anlık FV panel gücüne karş111k gelmektedir. $\mathrm{Bu}$ durum yükler tarafından yüksek güç talebi ya da düşük ışınım durumlarında ortaya çıkmaktadır. $\mathrm{Bu}$ çalışma modunda, yük gerilimlerini sabit tutmak ve yüklere kesintisiz güç sağlamak için FV panel batarya tarafından tamponlanmaktadır. Böylelikle, yükler hem FV panel hem de batarya tarafından beslenmektedir. Mod 2 ise yüklerin talep ettiği güçten daha yüksek bir anlık FV panel gücüne karşılık gelmektedir. Bu çalışma modunda, FV panelin arta kalan gücü bataryayı şarj eder. Böylelikle FV panel, yüklere kesintisiz güç sağlarken bataryayı da şarj etmektedir.

Güç akışı kontrolü ilgili kontrolcüler tarafından sağlanırken kontrol döngüleri arasındaki geçiş yönetim algoritması tarafından ayarlanmaktadır. Yük kontrol döngüleri sürekli olarak aktif olmasına rağmen MPPT, SA ve SG kontrol döngüleri arasında geçiş gerçekleştirilmektedir. MPPT, SA ve SG kontrol döngüleri aynı anahtarlama elemanını kontrol ettikleri için eş zamanlı çalışmamaktadırlar. Yük kontrol döngüsünün amac1, $S_{3}$ ve $S_{4}$ anahtarlama elemanlarını kullanarak yük gerilimlerinin regülasyonunu sağlamaktır. $S_{3}$ ve $S_{4}$ tetikleme sinyallerinin arasinda $180^{\circ}$ derece faz kaymas1 olup minimum \%5, maksimum \%50 görev döngüsü değerlerini alabilmektedirler. Görev döngüsü değeri yüklerin güç talebine göre PI kontrol yöntemi ile belirlenmektedir. Bu noktada, $\mathrm{S}_{3}$ anahtarının görev döngüsü değeri Yük-1'in gerilim regülasyonunu sağlarken, $\mathrm{S}_{4}$ anahtarının görev döngüsü değeri Yük-2'nin gerilim regülasyonun sağlamaktadır. MPPT kontrol döngüsünün amac1, FV panelinden maksimum gücü çıkarmaktır. Maksimum güç çıkarma işlemi, literatürde ve uygulamalarda düşük işlem yükü ve kullanım kolaylığı avantajlarından dolayı sıklıkla kullanılan Değiştir\&Gözlemle (P\&O) metodu ile gerçekleştirilmiştir. Kontrolcü, FV panelin çıkış gerilimini $\left(V_{f v}\right)$ /akımını $\left(I_{f v}\right)$ izlemekte ve anlık 
mevcut gücünü hesaplamaktadır. Ayrıca, kontrolcü hesaplanan güç değişimini dikkate alarak FV panel çıkış gerilimini belirli bir yönde değiştirerek güç değişimini gözlemlemektedir. Böylelikle, MPPT kontrol döngüsü hesaplanan güce bağlı olarak görev döngüsü değerini dinamik olarak hesaplamakta ve $S_{1}$ ve $S_{2}$ anahtarlarını tetiklemektedir. SA kontrol döngüsünün amac1, anlık FV panel gücünün yüklerin toplam gücünden büyük olduğu zamanlarda bataryanın sabit akım ile şarj edilmesini sağlamaktır. Sabit akım değeri veya diğer bir deyişle maksimum şarj akımı batarya nominal kapasitesinin yarısına denk gelmektedir. Sistemde kullanılmakta olan batarya nominal kapasitesi 100 Ah olarak belirlenmiştir. Bu nedenle, batarya maksimum 50 A ile şarj edilebilmektedir. SA kontrol döngüsü, ölçülen batarya şarj akımı $\left(I_{b}\right)$ ile referans $\left(I_{b r e f}\right) 50$ A değerlerini karşılaştırıp çıkan hata değerini $\left(I_{b e r r}\right)$ PI kontrolcüye uygulayarak $S_{1}$ ve $S_{2}$ anahtarlarının görev döngüsü değerlerini belirlemektedir. SA kontrol döngüsünü SG kontrol döngüsü takip eder. SA kontrolünün devamı olarak nitelendirilebilen bu kontrol döngüsü bataryanın belirlenen maksimum gerilim değerine ulaşmasından sonra aktifleşmektedir. SG kontrolü esnasında batarya paketlerinin şarj akımı üstel olarak düşer ve şarj akımı batarya nominal kapasitesinin \%0,5'ine ulaşınca şarj işlemi sone rer. SG kontrol döngüsü, ölçülen batarya gerilimi $\left(V_{b}\right)$ ile referans $\left(V_{\text {bref }}\right)$ 82,5 V değerlerini karşılaştırıp çıkan hata değerini $\left(V_{\text {berr }}\right)$ PI kontrolcüye uygulayarak $S_{1}$ ve $S_{2}$ anahtarlarının görev döngüsü değerlerini belirlemektedir.

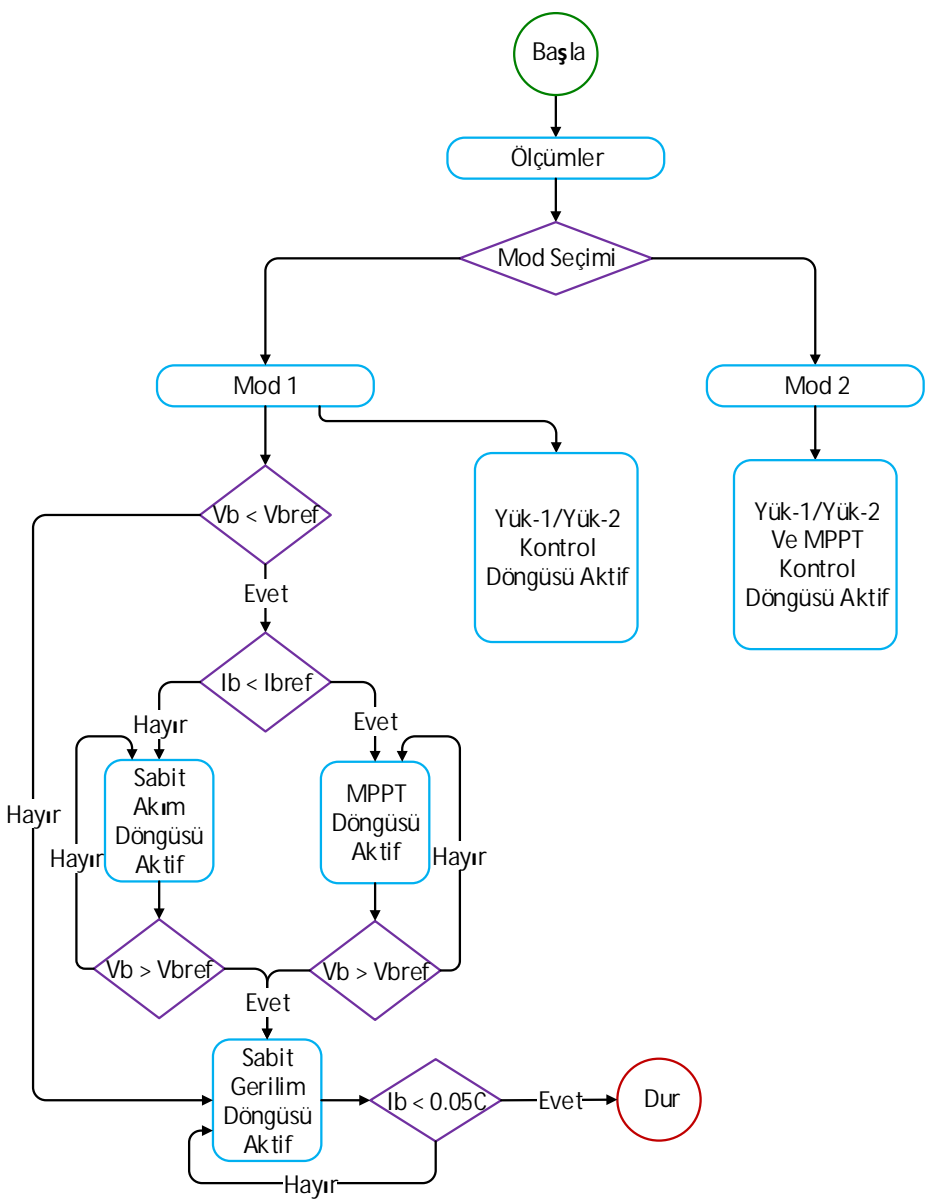

Şekil 5. Yönetim algoritması 


\section{PERFORMANS ANALIZI}

Önerilen interleaved DA-DA dönüştürücü tabanlı izole edilmiş çok bağlantı noktalı DA-DA dönüştürücünün ve kontrolcünün benzetim çalışmaları ve performans incelemeleri PSIM ortamında gerçekleştirilmiştir. Benzetim çalışmalarında, 1Soltech firmasına ait 1sth-215-p 7 paralel 7 seri FV panel kullanılarak $10 \mathrm{~kW}$ güç elde edilmiştir. Ayrıca, 72 V 100 A batarya kullanılarak FV panel desteklenmiştir. Yükler 60 $\mathrm{V}$ ve $40 \mathrm{~V}$ gerilim seviyelerine sahip olup güç tüketimleri benzetim çalışmalarında her birisi için azami $2 \mathrm{~kW}$ olarak belirlenmiştir. Benzetim modelinin parametreleri Çizelge 1'de verilmektedir. Önerilen sistemin bütün modlarının ve kontrol döngülerinin performans testleri iki durum çalışması altında gerçekleştirilmiştir. Bu durum çalışmaları Çizelge 2'de özetlenmektedir.

Çizelge 1. Sistem parametreleri

\begin{tabular}{|c|c|c|}
\hline Sistem & Parametre & Değer \\
\hline \multirow{3}{*}{ FV panel } & FV maksimum gücü $\left(1000 \mathrm{~W} / \mathrm{m}^{2}\right)$ & $10500 \mathrm{~W}$ \\
\hline & Maksimum güç noktası gerilimi $\left(1000 \mathrm{~W} / \mathrm{m}^{2}\right)$ & $207 \mathrm{~V}$ \\
\hline & Maksimum güç noktası akımı $\left(1000 \mathrm{~W} / \mathrm{m}^{2}\right)$ & $50 \mathrm{~A}$ \\
\hline \multirow{4}{*}{ Batarya } & Batarya kapasitesi & $100 \mathrm{Ah}$ \\
\hline & Batarya nominal gerilimi & $72 \mathrm{~V}$ \\
\hline & Batarya maksimum şarj gerilimi & $82.5 \mathrm{~V}$ \\
\hline & Batarya maksimum şarj akımı & $50 \mathrm{~A}$ \\
\hline \multirow{2}{*}{$\begin{array}{c}\text { Interleaved } \\
\text { dönüştürücü }\end{array}$} & Endüktör $\left(\mathrm{I}_{\mathrm{L} 1}\right)$ & $20 \mathrm{uH}$ \\
\hline & Endüktör ( $\left.\mathrm{I}_{\mathrm{L} 2}\right)$ & $20 \mathrm{uH}$ \\
\hline \multirow{9}{*}{ Genel } & Nominal yük 1 gerilimi & $60 \mathrm{~V}$ \\
\hline & Yük 1 çıkış kapasitesi & $1 \mathrm{mF}$ \\
\hline & Nominal yük 2 gerilimi & $40 \mathrm{~V}$ \\
\hline & Yük 2 çıkış kapasitesi & $1 \mathrm{mF}$ \\
\hline & Anahtarlama frekans1 & $20 \mathrm{kHz}$ \\
\hline & YFT mıknatıslanma endüktansı & $1 \mathrm{mH}$ \\
\hline & YFT birincil kaçak endüktansı & $4 \mathrm{uH}$ \\
\hline & YFT ikincil kaçak endüktansı & $4 \mathrm{uH}$ \\
\hline & YFT dönüşüm oranı & $1: 1$ \\
\hline
\end{tabular}

Çizelge 2. Durum çalışmaları

\begin{tabular}{|l|c|c|c|c|c|c|c|}
\hline & \multicolumn{4}{|c|}{ Durum çalışması 1 } & \multicolumn{3}{c|}{ Durum çalışması 2 } \\
\hline Zaman (s) & $0-0,02$ & $0,02-0,04$ & $0,04-0,063$ & $0,063-0,08$ & $0-0,02$ & $0,02-0,04$ & $0,04-0,06$ \\
\hline Işınım $\left(\mathbf{W} / \mathbf{m}^{\mathbf{2}}\right)$ & 300 & 600 & 1000 & 1000 & 350 & 350 & 350 \\
\hline Sıcaklık ( $\left.{ }^{\circ} \mathbf{C}\right)$ & 25 & 25 & 25 & 25 & 25 & 25 & 25 \\
\hline Yük-1 güç (W) & 2000 & 2000 & 2000 & 2000 & 2000 & 1000 & 1000 \\
\hline Yük-2 güç (W) & 2000 & 2000 & 2000 & 2000 & 2000 & 2000 & 1500 \\
\hline $\begin{array}{l}\text { Batarya } \\
\text { şarj/Deşarj }\end{array}$ & Deşarj & Şarj & $\begin{array}{c}\text { Sabit akım } \\
\text { şarj }\end{array}$ & $\begin{array}{c}\text { Sabit } \\
\text { gerilim şarj }\end{array}$ & Deşarj & Şarj & Şarj \\
\hline Mod & Mod 1 & Mod 2 & Mod 2 & Mod 2 & Mod 1 & Mod 2 & Mod 2 \\
\hline
\end{tabular}


Birinci durum çalş̧masında, hem FV panelden batarya ve yüklere hem de FV panel ve bataryadan yüklere güç transferi durumları incelenmiştir. Bunların yanı sıra, batarya şarj durumu esnasında MPPT ve batarya şarj algoritmalarının performansları da değerlendirilmiştir. Birinci durum çalışmasında bahsi geçen güç transfer durumları ve kontrol döngülerinin yanı sıra bu modlar ve döngüler arasındaki geçişler de incelenmiştir. 0-0,02 sn'lik kararlı hal zaman aralığı, $300 \mathrm{~W} / \mathrm{m}^{2}$ ışınım değeri, $25^{\circ} \mathrm{C}$ sıcaklık ve $4 \mathrm{~kW}$ 'lı toplam yük talebi ile mod 1'i temsil etmektedir. Bu zaman aralığında FV panel anlık güç üretim değeri yüklerin talep ettiği toplam güç değerinden düşüktür. $\mathrm{Bu}$ nedenle, yüklere kesintisiz güç sağlanması için batarya deşarj olmaktadır. İlgili zaman aralığında MPPT ve yük kontrol döngüleri aktiftir.

Birinci durum çalışmasının 0,02 sn'sinde PV'nin 1şınım değeri $300 \mathrm{~W} / \mathrm{m}^{2}$ değerinden $600 \mathrm{~W} / \mathrm{m}^{2}$ değerine çıartılarak sistemin geçici hal durumundaki dinamik tepkisi gözlemlenmiştir. 0,02-0,04 sn'lik kararlı hal zaman aralı̆ $600 \mathrm{~W} / \mathrm{m}^{2}$ 1şınım değeri, $25^{\circ} \mathrm{C}$ ve $4 \mathrm{~kW}$ 'llk toplam yük talebi ile mod 2 'yi temsil etmektedir. Bu zaman aralığında FV panelin anlık güç üretim değeri yüklerin talep ettiği toplam güç değerinden büyüktür. FV panelin arta kalan gücü bataryay1 şarj etmektedir. Batarya şarj akımı belirlenen maksimum şarj akımından az olduğu için ilgili çalışma aralığında MPPT ve yük kontrol döngüleri aktiftir.

Birinci durum çalışmasının 0,04 sn'sinde PV'nin 1şınım değeri $600 \mathrm{~W} / \mathrm{m}^{2}$ değerinden $1000 \mathrm{~W} / \mathrm{m}^{2}$ değerine artırılmış ve FV panelin gücü, üretebileceği maksimum değere ulaşmıştır. 0,04-0,063 sn'lik kararlı hal zaman aralığı, $1000 \mathrm{~W} / \mathrm{m}^{2}$ ş̧ınım değeri, $25{ }^{\circ} \mathrm{C}$ ve $4 \mathrm{~kW}$ 'llk toplam yük talebi ile mod 2'yi temsil etmektedir. FV panelin anlık güç üretiminin artışına paralel olarak batarya şarj akımı da artmış ve maksimum şarj akımı limitine ulaşmıştır. Bu nedenle, ilgili zaman aralığında MPPT kontrol döngüsü yerine SA kontrol döngüsü aktifleşerek $S_{1}$ ve $S_{2}$ anahtarlarını tetiklemeye başlamıştır. Yük gerilimleri yük kontrol döngüleri tarafından regüle edilmeye devam etmektedir. Batarya geriliminin birinci durum çalışmasının 0,063 sn'sinde belirlenen referans gerilime ulaşmasını takiben aktif kontrol döngüsü değişerek SG kontrol döngüsü devreye girmiştir. 0,063-0,08 sn zaman aralığındaki güç akışı mod 2'yi temsil ederken ilgili zaman aralığında $S G$ ve yük kontrol döngüleri aktiftir.

İkinci durum çalışmasında, önerilen topolojinin performansı FV panel ışınım ve sıcaklık değerleri sabit iken anlık yük değişimlerinde incelenmiştir. Şekil 7 ikinci durum çalışması performans dalga formlarını göstermektedir. İkinci durum çalışmasının 0-0,02 sn kararlı hal zaman aralığı, $350 \mathrm{~W} / \mathrm{m}^{2} 1$ şınım değeri, $25{ }^{\circ} \mathrm{C}$ ve $2+2 \mathrm{~kW}$ yük talepleri ile mod 1'i temsil etmektedir. İlgili zaman aralığında FV panel yükleri beslerken batarya desteklemekte ve deşarj olmaktadır. İkinci durum çalışmasının 0,02 sn'sinde yük 1 ve yük 2'nin güç talepleri sirasiyla $1 \mathrm{~kW}$ ve $2 \mathrm{~kW}$ olarak değişmiştir. İlgili zamanda yüklerin FV panelden talep ettikleri güç anlık FV panel üretiminden az olduğu için batarya şarj olmaya başlamıştır. $\mathrm{Bu}$ nedenle, 0,02-0,04 sn zaman aralığı mod 2'yi temsil etmektedir. İkinci durum çalışmasının 0,04 sn'sinde yük 1 ve yük 2'nin güç talepleri sırasıyla $1 \mathrm{~kW}$ ve $1,5 \mathrm{~kW}$ olarak değişmiştir. İlgili zaman aralığında FV panel hem yükleri beslemekte hem de bataryayı şarj etmektedir.

Performans dalga formları güç akış varyasyonlarının yanı sıra önerilen dönüştürücü verimliliği hakkında da bilgi vermektedir. Belirlenen çalışma modları dikkate alındığında mod 1'in verimlilik değeri $\% 98$ olarak hesaplanırken, mod 2'nin verimlilik değeri sistemin aktif kontrol döngüsüne göre değişkenlik göstermektedir. Sistem mod 2 çalışma durumunda MPPT, SA ve SG kontrol döngüleri aktif iken verimlilik değerleri sırasıyla $\% 98, \% 98,5$ ve $\% 98,5$ olarak hesaplanmaktadır. Önerilen dönüştürücünün verimlilik değerleri, olası tüm güç akış1 koşullarında etkinliğini göstermektedir. 


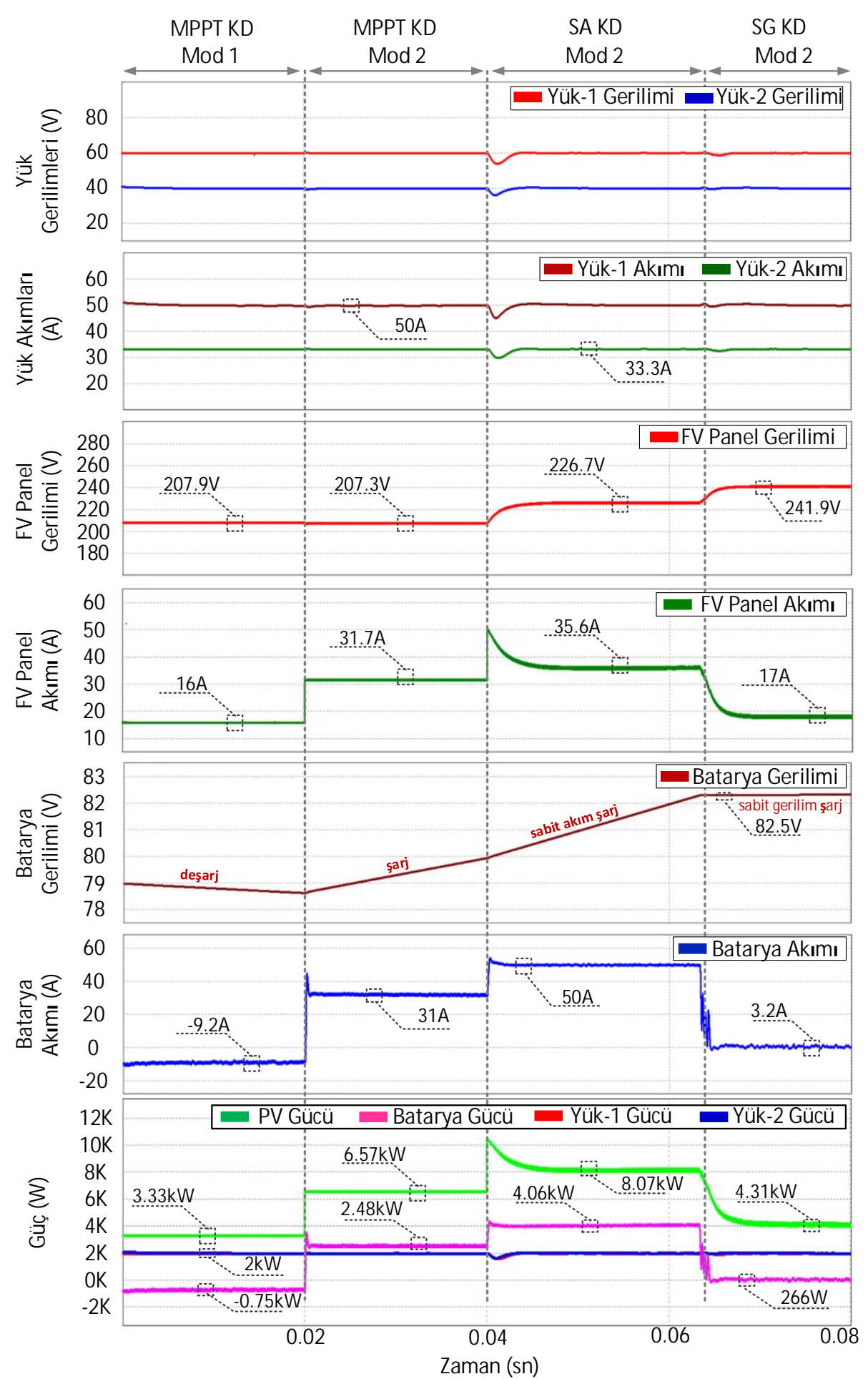

Şekil 6. Durum çalışması 1 performans analizi 
Fotovoltaik Panel ve Batarya Entegre Sistemler için Yeni Bir Interleaved Tabanlı Çok Portlu İzole DA-DA Dönüștürücü Analizi

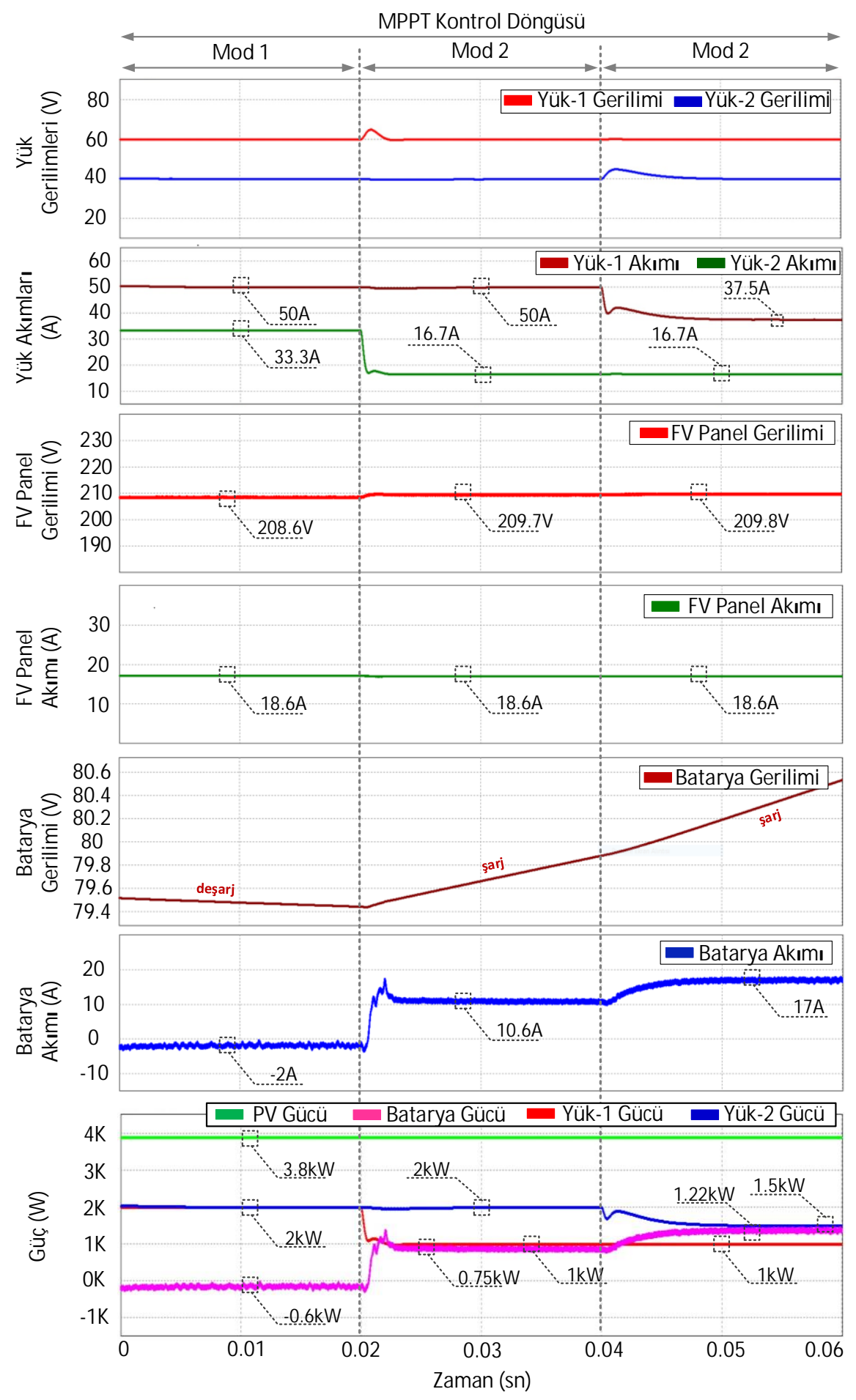

Şekil 7. Durum çalışması 2 performans analizi 


\section{SONUÇ}

$\mathrm{Bu}$ çalışma FV panel ile çalışan ve batarya ile destekli sistemler için etkin bir kontrol şemasına sahip interleaved tabanlı çift yönlü çalışabilen çok portlu izole yeni bir DA-DA dönüştürücü önermektedir. Önerilen dönüştürücünün başlıca avantajları şunlardır; (i) çeşitli enerji üretim/depolama birimleri için çoklu giriş bağlantı noktaları ve birbirinden bağımsı kontrol edilebilen çift çıkış bağlantı noktası, (ii) ek dönüştürücüye veya fazladan anahtarlama elemanına ihtiyaç duymadan nispeten düşük gerilimli batarya entegrasyonu, (iii) düşük anahtarlama elemanı sayısı ile düşük maliyetli bir dönüştürücü, (iv) kontrol döngüleri arasında anlık geçişe izin veren çok döngülü bir kontrol yapısı. Önerilen çok portlu dönüştürücünün etkinliği, çeşitli çalışma koşulları altında değerlendirilmiştir. Sonuçlar, önerilen çoklu bağlantı noktasına sahip dönüştürücünün tüm güç akış varyasyonlarını yüksek verimlilikle (>\%98) gerçekleştirebildiğini göstermektedir. Önerilen sistem kararlı hal koşullarında yüksek performans göstermekte ve bunun yanı sıra, geçici hal koşullar sırasında kontrol döngüleri arasında yumuşak geçişler ile etkin güç aktarımı sağlamaktadır.

\section{KAYNAKLAR}

1. Savrun, M.M., 2021. Z-source Converter Integrated dc Electric Spring for Power Quality Improvement in dc Microgris. Engineering Science and Technology, an International Journal, in press, doi: 10.1016/j.jestch. 2021.05.004.

2. Savrun, M.M., Atay, A., 2021. High Voltage Gain Multi-port Bidirectional DC-DC Converter with an Effective Multi-loop Control Strategy for PV/Battery Integrated Systems. European Mechanical Science, 5(3), 99-104.

3. Singh, R.K., Mishra, S., 2013. A Magnetically Coupled Feedback-clamped Optimal Bidirectional Battery Charger. IEEE Trans. Ind. Electron., 60(2), 422-432.

4. Das, M., Agarwal, V., 2016. Design and Analysis of a High-efficiency DC-DC Converter with Soft Switching Capability for
Renewable Energy Applications Requiring High Voltage Gain. IEEE Trans. Ind. Electron., 63(5), 2936-2944.

5. Alhatlani, A., Batarseh, I., 2019. Review of Partially Isolated Three-port Converters for PV-Battery Systems That Interface a PV, Bidirectional Battery, and Load. IEEE Conf. Power Electron. Renew. Energy, CPERE 2019, 465-472.

6. Bhattacharjee, A.K., Kutkut, N., Batarseh, I., 2018. Review of Multiport Converters for Solar and Energy Storage Integration. IEEE Trans. Power Electron., 34(2), 1431-1445.

7. Moradisizkoohi, H., Elsayad, N., Mohammed, O.A., 2019. A Family of Three-port Threelevel Converter Based on Asymmetrical Bidirectional Half-bridge Topology for Fuel Cell Electric Vehicle Applications. IEEE Trans. Power Electron., 34(12), 11706-11724.

8. Zhang, N., Sutanto, D., Muttaqi, K.M., 2016. A Review of Topologies of Three-port DC-DC Converters for the Integration of Renewable Energy and Energy Storage System. Renew. Sustain. Energy Rev., 56, 388-401.

9. Jyotheeswara Reddy, K., Natarajan, S., 2018. Energy Sources and Multi-input DC-DC Converters Used in Hybrid Electric Vehicle Applications-A Review. Int. J. Hydrogen Energy, 43(36), 17387-17408.

10. Sato, Y., Uno, M., Nagata, H., 2020. Nonisolated Multiport Converters Based on Integration of PWM Converter and Phase-shiftswitched Capacitor Converter. IEEE Trans. Power Electron., 35(1), 455-470.

11. Ganjavi, A., Ghoreishy H., Ahmad, A.A., 2018. A Novel Single-1nput Dual-output Threelevel. IEEE Transactions on Industrial Electronics, 65(10), 8101-8111.

12. Faraji, R., 2018. Soft-switched Nonisolated High Step-up Three-port. IEEE Trans. Power Electron., 33(12), 10101-10111.

13. Gan, C., Jin, N., Sun, Q., Kong, W., Hu, Y., Tolbert, L.M., 2018. Multiport Bidirectional SRM Drives for Solar-assisted Hybrid Electric Bus Powertrain with Flexible Driving and Selfcharging Functions. IEEE Trans. Power Electron., 33(10), 8231-8245.

14. Xue, F., Yu, R., Huang, A.Q., 2017. A $98.3 \%$ Efficient GaN Isolated Bidirectional DC-DC 
Converter for DC Microgrid Energy Storage System Applications. IEEE Transactions on Industrial Electronics, 64(11), 9094-9103.

15. Ding, Z., Yang, C., Zhang, Z., Wang, C., Xie, S., 2014. A Novel Soft-switching Multiport Bidirectional DC-DC Converter for Hybrid Energy Storage System. IEEE Trans. Power Electron., 29(4), 1595-1609.

16. Liu, D., Li, H., 2006. A ZVS Bi-directional DC-DC Converter for Multiple Energy Storage Elements. IEEE Trans. Power Electron, 21(5), 1513-1517.

17. Sathyan, S., Suryawanshi, H.M., Shitole, A.B., Ballal, M.S., Borghate, V.B., 2018. Softswitched Interleaved DC/DC Converter as Front-end of Multi-inverter Structure for Micro Grid Applications. IEEE Trans. Power Electron., 33(9), 7645-7655.

18. Falcones, S., Ayyanar, R., Mao, X., 2013. A DC-DC Multiport-converter-based Solid-state. IEEE Transactions on Power Electronics, 28(5), 2192-2203.

19. Tao, H., Kotsopoulos, A., Duarte, J.L., Hendrix, M.A.M., 2008. Transformer-coupled Multiport ZVS Bidirectional DC-DC Converter with Wide Input Range. IEEE Trans. Power Electron., 23(2), 771-781.

20. Karthikeyan, V., Gupta, R., 2018. Multipleinput Configuration of Isolated Bidirectional DC-DC Converter for Power Flow Control in Combinational Battery Storage. IEEE Trans. Ind. Informatics, 14(1), 2-11.

21.Zhang, Z., Thomsen, O.C., Andersen, M.A.E., Nielsen, H.R., 2012. Dual-input Isolated Fullbridge Boost DC-DC Converter Based on the Distributed Transformers. IET Power Electron., 5(7), 1074-1083.

22. Tao, H., Duarte, J.L., Hendrix, M.A.M., 2008. Three-port Triple-half-bridge Bidirectional Converter with Zero-voltage Switching. IEEE Trans. Power Electron., 23(2), 782-792.

23. Dusmez, S., Li, X., Akin, B., 2016. A New Multiinput Three-level DC/DC Converter. IEEE Trans. Power Electron., 31(2), 12301240.

24.Zeng, J., Qiao, W., Qu, L., 2015. An Isolated Three-port Bidirectional DC-DC Converter for Photovoltaic Systems with Energy Storage. IEEE Trans. Ind. Appl., 51(4), 3493-3503.
25. Jianwu, Z., Wei, Q., Liyan, Q., Jiao, Y., 2014. An Isolated Multiport DC-DC Converter for Simultaneous Power Management of Multiple Different Renewable Energy Sources. IEEE J. Emerg. Sel. Top. Power Electron., 2(1), 70-78.

26. Savrun, M.M., Atay, A., 2020. Multiport Bidirectional DC-DC Converter for PV Powered Electric Vehicle Equipped with Battery and Supercapacitor. IET Power Electron., 13(17), 3931-3939.

27. Hong, J., Yin, J., Liu, Y., Peng, J., Jiang, H., 2019. Energy Management and Control Strategy of Photovoltaic/Battery Hybrid Distributed Power Generation Systems with an Integrated Three-Port Power Converter. IEEE Access, 7, 82838-82847.

28. Wu, H., Jia, Y., Yang, F., Zhu, L., Xing, Y., 2020. Two-stage Isolated Bidirectional DC-AC Converters with Three-port Converters and Two DC Buses. IEEE Journal of Emerging and Selected Topics in Power Electronics, 8(4), 4428-4439.

29. Wu, H., Zhang, J., Qin, X., Mu, T., Xing, Y., 2016. Secondary-side-regulated Soft-Switching Full-Bridge Three-port Converter Based on Bridgeless Boost Rectifier and Bidirectional Converter for Multiple Energy Interface. IEEE Transactions on Power Electronics, 31, 4847-4860.

30. Ding, Z., Yang, C., Zhang, Z., Wang, C., Xie, S., 2014. A Novel Soft-switching Multiport Bidirectional DC-DC Converter for Hybrid Energy Storage System. IEEE Transactions on Power Electronics, 29, 1595-1609.

31. Wu, F., Wang, K., Luo, S., 2021. Hybrid-threelevel Current-fed series-resonant Isolated DCDC Converter and its Optimization Modulation Strategy. IEEE Transactions on Power Electronics, in press doi: 10.1109/TPEL. 2021.3098452. 